\title{
Evaluation Index System and Comprehensive Evaluation Methods of the Power Grid Infrastructure Projects
}

\author{
Zhendong Du ${ }^{1, a}$, Hua Weng ${ }^{2, b}$, Dunnan Liu ${ }^{3, c}$, Tianqi Tang ${ }^{4, d}$ and Jiawei \\ Zhao ${ }^{5, e}$ \\ ${ }^{1,2}$ Economic Research Institute of State Grid Zhejiang Electric Power Company, Hangzhou 310008, \\ China \\ 3,4,5 North China Electric Power University, Beijing 102206,P.R.China

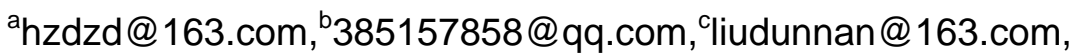 \\ d715437085@qq.com, ${ }^{\mathrm{e}}$ zhaojw923@163.com
}

Keywords: the power grid infrastructure key investment projects; investment benefit, index system; comprehensive evaluation

Abstract. With the development of China economy the demand of electric power is increasing. Power grid entered a rapid development stage and a series of problems about power grid construction projects' investment is becoming more and more attention. First, combined with the content of the power grid infrastructure key investment projects and the analysis of characteristic, the investment benefit evaluation index system is constructed from four aspects concluding the economic benefit, the technical level, coordinated benefit and the social benefits in this paper. Second, using set-valued iteration method for the determination of index weight and using linear weighting method, ideal method and Romanian method to make comprehensive evaluation of three key investment project. Third, by comparing those methods and sensitivity analysis, get all the three methods can be used for the power grid infrastructure key investment projects and the main influencing index. Finally, in this paper, by analyzing the results, combining with the characteristics of the power grid infrastructure key investment projects, puts forward prospect of the power grid infrastructure key investment projects.

\section{Introduction}

With the development of China economy, the demand of electric power is increasing. The power grid construction entered a rapid development stage and the power supply situation of power grid enterprise gradually become tense. In order to promote the coordinated development, the power grid enterprises need to intensify the building of electric power infrastructure projects to meet the needs of the areas. the power grid infrastructure projects is great investment, long construction period and large resource consumption. Those projects have large impact on society and environment. The investment benefit of those projects is closely related to investment level of power grid enterprises, especially for the key projects. So, it is very important for the power grid construction to make a comprehensive evaluation of each key projects by comparing each investment benefit.

In order to serve the economic development of China, power grid enterprises should increase and optimize capital input of power grid investment. In this case, the rapid development of China's power grid investment has become inevitable. In the face of the big investment scale, those have become increasingly concerned topic for power grid enterprises: determining the investment strategy of the power grid construction scientifically, establishing perfect project investment optimization control method and eliminating the phenomenon such as duplication of investment or waste of investment. By researching the key investment projects, we can know the relation between the power grid infrastructure key investment projects and the development of power grid deeply. 


\section{1. the construction and pretreatment of the power grid infrastructure investment projects investment benefit evaluation index}

1.1the construction of the power grid infrastructure investment projects investment benefit evaluation index system

Combining present situation of the power grid infrastructure key investment projects in China, the investment benefit evaluation index system about the power grid infrastructure key investment projects is constructed from four aspects concluding the economic benefit, the technical level, coordinated benefit of the power grid development and the social benefits in this paper. The frame is as follows:

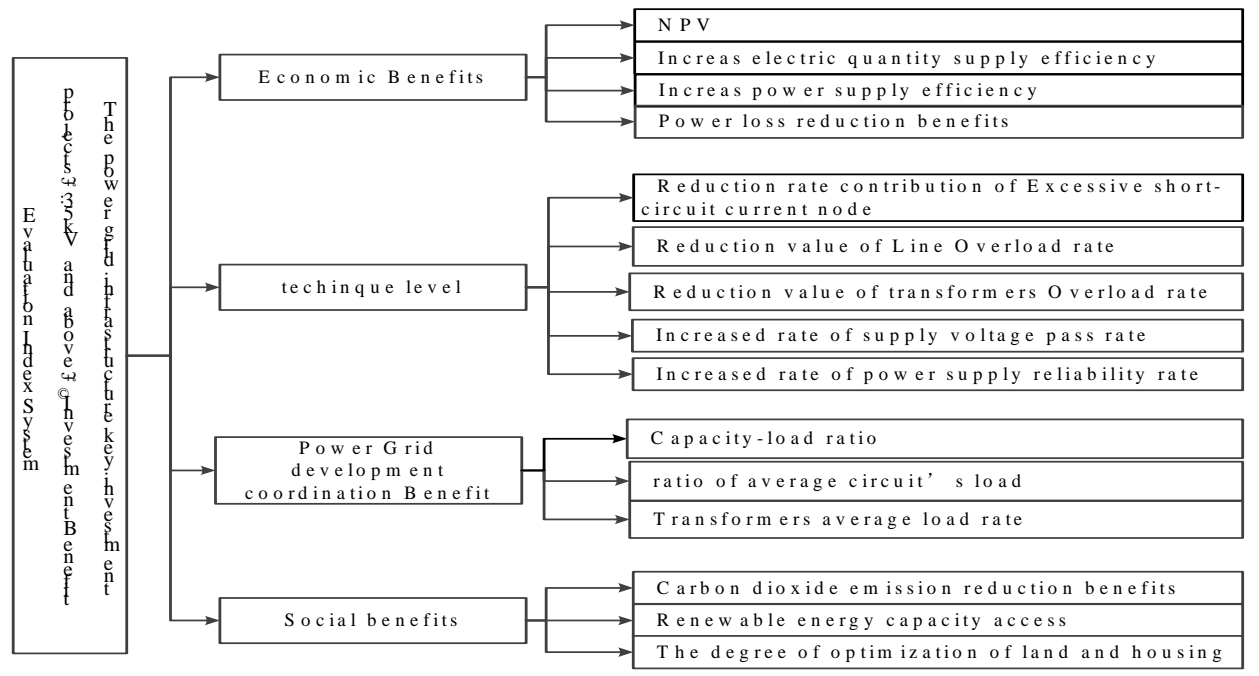

1.2 unification and dimensionless for evaluation index.In the process of the index selection, there are four types of index: maximum index, minimum index, middle index and interval index. If the index includes all the four types of index, before the comprehensive evaluation of the scheme, index must be consistent. After index consistency, standardized method may be used for dimensionless. Processing results are as follows:

\section{The determination of the set-valued iteration method's weight}

Let labeled as $X=\left\{x_{i}, x_{2}, \ldots, x_{m}\right\}$, Select eight experts, then let each expert select 10 indexes that he considers more important in the labeled. The k-expert selected is a subset of $\mathrm{X}$ :

$$
\begin{gathered}
X(k)=\left\{x_{1}(k), x_{2}(k), \ldots, x_{10}(k)\right\} \text {. Build indicator function, According to the formula } \\
u_{k}\left(x_{j}\right)=\left\{\begin{array}{l}
1, x_{j} \in X(k) \\
0, x_{j} \notin X(k)
\end{array}\right.
\end{gathered}
$$

The selection of each experts can be obtained as table 1.After the expert selection,

$$
g\left(x_{j}\right)=\sum_{k=1}^{L} u_{k}\left(x_{j}\right)
$$

ratio $g\left(x_{j}\right) / \sum g\left(x_{j}\right)$ seen as index's $\left({ }^{x_{j}}\right)$ Weight coefficient $\left({ }^{w_{j}}\right)$. The calculation process and results shown in Table 1. 
Table 1 Statistics of expert selection

\begin{tabular}{|c|c|c|c|c|c|c|c|c|c|c|c|c|}
\hline target layer & second grade indexes & third grade indexes & L1 & $\mathrm{L} 2$ & L3 & L4 & L5 & L6 & L7 & L8 & Statistics & Weights \\
\hline \multirow{16}{*}{$\mathrm{O}$} & \multirow{4}{*}{ A1 } & A11 & 1 & 1 & 1 & 1 & 1 & 1 & 1 & 1 & 8 & 0.13 \\
\hline & & A12 & 0 & 1 & 1 & 0 & 1 & 0 & 0 & 1 & 4 & 0.06 \\
\hline & & A13 & 0 & 0 & 0 & 1 & 0 & 1 & 1 & 0 & 3 & 0.05 \\
\hline & & A14 & 1 & 0 & 0 & 1 & 0 & 1 & 1 & 0 & 4 & 0.06 \\
\hline & \multirow{5}{*}{ A2 } & A21 & 1 & 1 & 0 & 1 & 1 & 1 & 1 & 0 & 6 & 0.09 \\
\hline & & A22 & 0 & 0 & 0 & 1 & 1 & 1 & 0 & 1 & 4 & 0.06 \\
\hline & & A23 & 1 & 0 & 1 & 0 & 0 & 0 & 0 & 1 & 3 & 0.05 \\
\hline & & A24 & 0 & 1 & 1 & 0 & 0 & 0 & 0 & 0 & 2 & 0.03 \\
\hline & & A25 & 1 & 1 & 1 & 0 & 1 & 1 & 1 & 0 & 6 & 0.09 \\
\hline & \multirow{3}{*}{ A3 } & A31 & 1 & 1 & 1 & 0 & 1 & 1 & 1 & 1 & 7 & 0.11 \\
\hline & & A32 & 0 & 1 & 0 & 1 & 1 & 0 & 0 & 1 & 4 & 0.06 \\
\hline & & A33 & 0 & 0 & 1 & 1 & 0 & 0 & 0 & 0 & 2 & 0.03 \\
\hline & \multirow{4}{*}{ A4 } & A41 & 1 & 1 & 1 & 1 & 1 & 1 & 1 & 0 & 7 & 0.11 \\
\hline & & A42 & 1 & 0 & 0 & 0 & 0 & 0 & 1 & 1 & 3 & 0.05 \\
\hline & & A43 & 0 & 0 & 0 & 0 & 0 & 0 & 0 & 1 & 1 & 0.02 \\
\hline & & & 8 & 8 & 8 & 8 & 8 & 8 & 8 & 8 & 64 & 1 \\
\hline
\end{tabular}

\section{3. comprehensive evaluation based on different evaluation methods}

\section{1comprehensive evaluation based on linear weighting method}

Known data samples and index weight, According to the formula

$$
y_{i}=\sum_{j=1}^{m} x_{i j} \omega_{j}
$$

comprehensive evaluation object can be determined evaluation values are as Table 2:

Table 2 Comprehensive Evaluation of the results of the linear weighting method

\begin{tabular}{|c|c|c|}
\hline Investment projects & Comprehensive evaluation value & rank \\
\hline Area 1 & 0.3476 & 2 \\
\hline Area 2 & 0.5273 & 1 \\
\hline Area 3 & 0.1250 & 3 \\
\hline
\end{tabular}

Table4 Evaluation results of Ideal Point Method

\begin{tabular}{|r|c|c|}
\hline & Relative Closeness & rank \\
\hline Area 1 & 0.44101 & 2 \\
\hline Area 2 & 0.64812 & 1 \\
\hline
\end{tabular}

It is obvious that the investment benefit is the best in area 2 .

\section{2comprehensive evaluation based on ideal method}

(1)The dimensionless original data indexes, as follows:

Table 3 Decision Matrix-- Normalization method

\begin{tabular}{|c|c|c|c|c|c|c|c|c|c|c|c|c|c|c|c|}
\hline & $\mathrm{A}_{11}$ & $\mathrm{~A}_{12}$ & $\mathrm{~A}_{13}$ & $\mathrm{~A}_{14}$ & $\mathrm{~A}_{21}$ & $\mathrm{~A}_{22}$ & $\mathrm{~A}_{23}$ & $\mathrm{~A}_{24}$ & $\mathrm{~A}_{25}$ & $\mathrm{~A}_{31}$ & $\mathrm{~A}_{32}$ & $\mathrm{~A}_{33}$ & $\mathrm{~A}_{41}$ & $\mathrm{~A}_{42}$ & $\mathrm{~A}_{43}$ \\
\hline Area 1 & 0.71 & 0.61 & 0.47 & 0.77 & 0.54 & 0.47 & 0.44 & 0.73 & 0.74 & 0.55 & 0.56 & 0.58 & 0.69 & 0.70 & 0.57 \\
\hline Area 2 & 0.46 & 0.63 & 0.62 & 0.45 & 0.64 & 0.72 & 0.90 & 0.43 & 0.37 & 0.00 & 0.60 & 0.59 & 0.57 & 0.56 & 0.59 \\
\hline Area 3 & 0.53 & 0.47 & 0.63 & 0.46 & 0.55 & 0.50 & 0.04 & 0.53 & 0.56 & 0.83 & 0.57 & 0.57 & 0.45 & 0.44 & 0.57 \\
\hline
\end{tabular}

(2)Initially identified positive ideal points by the above indicators are:

$X^{+}=(0.71,0.63,0.63,0.77,0.64,0.72,0.90,0.73,0.74,0.83,0.60,0.59,0.69,0.70,0.59)$

Negative ideal points are:

$$
X^{-}=(0.46,0.47,0.47,0.45,0.54,0.47,0.04,0.43,0.37,0,0.56,0.57,0.45,0.44,0.57)
$$

(3)Calculate the relative closeness degree

According to the formula

$$
d_{i}=\frac{\left\langle\Delta u_{i}, \Delta u\right\rangle}{\|\Delta u\|^{2}}, i=1,2, \ldots, n
$$

Closeness of three projects as shown in Table 4.

By the results of Tops is comprehensive evaluation model, the relative closeness is bigger, explaining the area 2 from the negative ideal solution is the largest. So it is obvious that the investment benefit is the best in area 2 and investment benefit is the worst in area 3 . 


\section{3comprehensive evaluation based on Romanian method}

At first, The characterization of each index specific values into a score out of 100 and this step is called standardization. Respectively to compare scores from each program when standardized indexes,. The best solution was 100 points, 1 point for the worst scenario, the following formula was centered program scores:

$$
X=[99 *(C-B) /(A+B)]+1
$$

In the formula, $A$ is the variable value for the best solution, $B$ for the worst solution, $C$ for the centered solution, $X$ is score of the centered solution. At first, the data were normalized to the respective programs, shown as table 5 .

Table 5 Comprehensive evaluation results of the Romanian method

\begin{tabular}{|c|c|c|c|c|c|c|}
\hline target layer & second grade indexes & Third grade indexes & Area 1 & Area 2 & Area 3 & Weights \\
\hline \multirow{15}{*}{0} & \multirow{4}{*}{ A1 } & A11 & 100 & 1 & 29.66 & 0.0315 \\
\hline & & A12 & 84.64 & 100 & 1 & 0.0146 \\
\hline & & A13 & 1 & 93.4 & 100 & 0.0147 \\
\hline & & A14 & 100 & 1 & 5.25 & 0.06425 \\
\hline & \multirow{5}{*}{ A2 } & A21 & 1 & 100 & 15.14 & 0.00535 \\
\hline & & A22 & 1 & 100 & 13.38 & 0.03548 \\
\hline & & A23 & 1 & 100 & 1 & 0.6519 \\
\hline & & A24 & 100 & 1 & 34 & 0.04615 \\
\hline & & A25 & 100 & 1 & 50.5 & 0.07102 \\
\hline & \multirow{3}{*}{ A3 } & A31 & 67 & 1 & 100 & 0.00044 \\
\hline & & A32 & 1 & 100 & 21.74 & 0.00103 \\
\hline & & A33 & 42.44 & 100 & 1 & 0.00021 \\
\hline & \multirow{3}{*}{ A4 } & A41 & 100 & 49.22 & 1 & 0.02929 \\
\hline & & A42 & 100 & 44.81 & 1 & 0.03399 \\
\hline & & A43 & 1 & 100 & 1 & 0.00009 \\
\hline
\end{tabular}

By the table, the weighted fractional of three areas can be available, area 1 is 29.60 , area 2 is 75.42 and area 3 is 9.23 .

The situation for the investment benefit of three areas is as follows: area $2>$ area $1>$ area3

\subsection{Comprehensive Analysis and Evaluation}

From the above evaluation result, using the three kinds of evaluation method to evaluate the investment benefit of the three areas reach the same conclusion: the investment benefit is the best in area 2 and investment benefit is the worst in area 3.

The four kinds of comprehensive evaluation method in this paper mainly contrast is as follows:

Table 6 Comprehensive Evaluation Method Comparison Table

\begin{tabular}{|c|c|c|c|c|}
\hline Method & $\begin{array}{c}\text { Weight } \\
\text { determination }\end{array}$ & $\begin{array}{l}\text { Determination form of evaluation } \\
\text { results }\end{array}$ & Criterion & results \\
\hline $\begin{array}{l}\text { Linear weighting } \\
\text { method }\end{array}$ & \multirow{3}{*}{$\begin{array}{l}\text { Entropy Method(the } \\
\text { method used in this } \\
\text { paper) }\end{array}$} & Relative Closeness & $\begin{array}{l}\text { Interval [0,1], The higher the } \\
\text { evaluation value, the better }\end{array}$ & \multirow{3}{*}{$\begin{array}{l}\text { Area 1- good } \\
\text { Area 2- excellent } \\
\text { Area 3-bad }\end{array}$} \\
\hline Romanian method & & Overall Rating score & $\begin{array}{l}\text { Interval [0,100], he higher the } \\
\text { evaluation value, the better }\end{array}$ & \\
\hline Ideal Point Method & & Comprehensive evaluation value & $\begin{array}{l}\text { Interval [0,1], he higher the } \\
\text { evaluation value, the better }\end{array}$ & \\
\hline
\end{tabular}

\subsection{The sensitivity analysis of evaluation results}

In the case of using the same unification and dimensionless, changing comprehensive evaluation method can not change the order of comprehensive evaluation results.

By making sensitivity analysis in this paper from the perspective of unification, dimensionless and comprehensive evaluation method. Dimensionless method weight less sensitivity to the evaluation results, weight determination method weight more sensitivity to the evaluation results and the choice of comprehensive evaluation method has no effect on comprehensive evaluation method.

\section{Conclusions and Prospects}

(1)The investment benefit evaluation index system about the power grid infrastructure investment projects is constructed from four aspects concluding the economic benefit, the technical level, 
coordinated benefit of the power grid development and the social benefits in this paper. Three areas have been evaluated and it laid the foundation for quantitative research behind.

(2)In this paper, for the evaluation of the power grid infrastructure key investment projects only consider static the evaluation of investment benefit. During the subsequent learning, the of grid investment projects can be made from the entire process of Investment projects and we should consider the dynamics of investment projects.

\section{References}

[1]HE Yong-xiou, LIU Dun-nan, LUO Tao, et al. Power Comprehensive Evaluation Method[M]. North China Electric Power University Press,2011.

[2]NIU Xiu-min, ZHENG Shao-zhi. Comparison of Several Conventional Comprehensive Evaluation Methods[J]. Statistics and Decision,2006,(3):142-143.

[3]GUO Ya-jun. the sensitive issue and Empirical Analysis f Comprehensive Evaluation results[N]. Manage Scientific Journals,1998,1(3):28-35. 